\title{
Factors associated with adherence of highly active antiretroviral therapy among adult HIVIAIDS patients in Mekelle Hospital Northern Ethiopia
}

\author{
Kiday Hailasillassie ${ }^{1}$, Belachew Etana ${ }^{2}$, Mussie Alemayehu ${ }^{1}$, Girmatsion Fisseha ${ }^{1,}$ * \\ ${ }^{1}$ School of Public Health, Reproductive Health and Nutrition team, Mekelle University, Mekelle, Ethiopia \\ ${ }^{2}$ School of Public Health, Health service Management Team, Mekelle University, Mekelle, Ethiopia

\section{Email address:} \\ hkiday@gmail.com (K. Hailasillassie), belachewetana@yahoo.com (B. Etana),mossalex75@gmail.com (M. Alemayehu), \\ girmaf4@yahoo.com (G. Fisseha)
}

\section{To cite this article:}

Kiday Hailasillassie, Belachew Etana, Mussie Alemayehu, Girmatsion Fisseha. Factors Associated with Adherence of Highly Active Antiretroviral Therapy among Adult HIV/AIDS Patients in Mekelle Hospital Northern Ethiopia. Science Journal of Public Health. Vol. 2, No. 4, 2014, pp. 367-372. doi: 10.11648/j.sjph.20140204.30

\begin{abstract}
Background: Drug adherence is the most important in progression of disease among HIV positive individuals under antiretroviral treatment. Besides, it is the main factor for survival. So the objective was to assess factors association with adherence of ART among adult people living with HIV/AIDS. Methods: A cross-sectional study was carried out among adult PLWHA attending HAART at Mekelle Hospital during June 2012. A total of 422 participants were recruited by systemic random sampling by daily patient load of ART clinic. Standard questionnaire was used to collect data after we pre-tested. The data was entered in to a computer by Epi-data 3.1 and analyzed using SPSS 20. Bivariate and multiple logistic regression analysis were done to determine factors associated with drug adherence. Odds ratio with their $95 \%$ confidence intervals and p-values less than 0.05 was considered as statistically significant association. Result: a total 403 people living on with HIV/AIDS were responded to the study with $95 \%$ response rate. The mean age of participants was 38.44 years and on average they were on ART for 3 years and 5 months on ART. A total adherence level was $63.4 \%$ and HIV positive who had their own income $(2.195 \%$ CI: $1.2,3.9)$, urban residence $(2.395 \%$ CI: $1.2,4.5)$ and being diagnosed in Mekelle Hospital (1.8 95\% CI: 1.2, 2.9) were independently predicts HAART adherence. Conclusion: Drug adherence level was very low in Mekelle hospital and patients place of residence, economic status and being diagnosed in Mekelle hospital were independent predictors for adherence. So, awareness creation for rural residence and income generation method should be created to increase adherence level.
\end{abstract}

Keywords: Drug Adherence, HAART, HIV Patients, Northern Ethiopia

\section{Introduction}

Globally, 34.0 million people were living with Human immunodeficiency virus (HIV) at the end of 2011. An estimated $0.8 \%$ of adults aged $15-49$ years worldwide are living with HIV, although the burden of the epidemic continues to vary considerably between countries and regions. Sub-Saharan Africa remains most severely affected region with nearly 1 in every 20 adults (4.9\%) living with HIV and accounting for $69 \%$ of the people living with HIV worldwide (1).

Ethiopia is among the countries seriously affected by the HIV epidemic. During 2011, the estimated adult prevalence is $1.5 \%$ and large number of people living with HIV which approximately about 800,000 (2).

Drug adherence is very important in progression of disease among HIV positive individuals under antiretroviral treatment (ART). It was showed that there is strong correlation between adherence and clinical outcomes like viral load and CD4 count. According to study done in London and Brighton, drug adherence is direly related with decrement of viral load from the baseline (3).

Among people living with HIV/AIDS, $95 \%$ of ART adherence rate needed to decrease the drug resistance and individual from susceptibility to opportunistic infection. Besides this, drug non-adherence is one of the main cause for treatment failure and drug resistance (4). Nonadherence has been found to diminish the immunological 
benefit of ART and increase AIDS-related morbidity, mortality and hospitalizations. Study done in Uganda showed that, drug non-adherence is related with the survival of patients infected with HIV and adherent individuals had a survival rate of four time than nonadherent patients (5).

Studies done before identified factors related with ART adherence were ranged from socio-demographic characteristics of the patients; clinical characteristics and health care service related problems were factors which are related with drug non-adherence among PLWHAs (6-9).

However, still little is known about what factors are related with adherence in the study area and it is difficult to generalize the study from other places for the population in northern Ethiopia. Therefore, this study is needed to fulfill knowledge gap in the northern part of the country for policy makers, researcher and other consumers of this research. So this study is aimed to assess adherence level of the patients and factors related with drug adherence among people living with HIV/AIDS in Mekelle hospital Northern Ethiopia. Beside this, this study is also helpful for program mangers and decision makers working in HIV/AIDS area for proper design and planning.

\section{Methods}

\subsection{Study Population and Area}

The study was conducted in Mekelle Hospital during June to July 2012 among People living with HIV/AIDS those registered under ART clinic. The hospital is giving service to more than 500,000 people living in Mekelle zone including the people coming from the nearby regions (Afar and Amhara) in addition; it is a training center for about 2,000 health science students, yearly. Currently there are 3,480 individuals on ART and out of this 3,116 are adults $(\geq 15$ years). Clients were enrolled into the study if they are above 18 years and had been on treatment for more than three months. Critically ill clients were excluded from the study.

\subsection{Study Design and Sample}

The study used a cross sectional study design and data was collected from adult PLWHA. A total sample of 422 was calculated using single population proportion formula using 50\% proportion of drug adherence, the absolute precision of $5 \%$ and with $95 \%$ confidence interval. The calculated sample size is 384 . To get the final sample size $10 \%$ non-response rate was added. The study subjects were selected by systematic random sampling after the daily client load was calculated prior to data collection. First average monthly patient load was calculated based last month's performance. Then daily patient load was calculated and systematic random sampling used to select the study subjects depend on the order they came to the ART clinic. In average 30 patients were expected to come to the clinic daily during the time of data collection, so every three patients were included into the study based on the inclusion criteria.

\subsection{Data Collection}

Interviewers administered a pre-tested structured questionnaire initially developed in English and later translated into Tigrigna was used for data collection. The questionnaire included parts on; socio-demographic characteristics of respondents, HIV/AIDS treatment related questions and questionnaire on adherence. In this study adherence was assessed by eight item Morisky medication adherence scale which is used for chronic conditions.

Respondents were interviewed at exit after they got their service by trained data collector. The logical order and acceptability of the questionnaire checked during pre-test which was done in similar setting. The overall data collection activity was controlled by the principal investigator of the study. All completed questionnaire was examined every day after data collection for completeness and consistency.

\subsection{Data Processing and Analysis}

Data was entered into the computer using Epi-data 3.1 and cleaned before analysis was done. Preliminary analysis and writing of the result was written researchers. Descriptive statistics was done to characterize the data by percentage and frequency. To identify independent predictors of HAART adherence among PLWHA, logistic regression analysis was carried out. First bivariate logistic regression analysis was done to see the associations of dependent and independent variables, then those variables which showed significant association were included in multiple logistic regression analysis to control possible confounders.

Eight items Morisky medication adherence scale was used to assess adherence level of the respondents. The respondents said to adherent, if he/she scores 8 out of eight answered correctly; otherwise they are said non-adherent to HAART.

\subsection{Ethical Considerations}

The study protocol was reviewed and approved by health research ethics review committee of the College of Health Sciences at Mekelle University. Permission to undertake the study was obtained from every relevant authority in Tigray regional health bureau and Mekelle hospital. Verbal informed consent was obtained from the participants prior to participation in the study, and data collection was conducted confidentially.

\section{Results}

\subsection{Socio-Demographic Characteristics of Participants}

A total of 403 of people living with HIV were participated in to the study with $95 \%$ of response rate. Mean age 38.44 and ranged from 21 to 66 years. About $89 \%$ of the 
respondents were from urban areas, while the remaining $10.4 \%$ were from rural area. Study participants were on ART in average for 3 years and 5 months with maximum of eight years.

Majority of the respondents were Tigrians (95.3\%) while about 93\% were followers orthodox Christianity. About 21\% of the respondents attended primary school, and majority the respondents work as daily huyyhlaborer as their main occupation (Table 1).

Table 1. Socio-demographic characteristics study participants, Mekelle Hospital, Tigray, Ethiopia

\begin{tabular}{|c|c|c|}
\hline Variables & Frequency & $\%$ \\
\hline \multicolumn{3}{|l|}{ Sex } \\
\hline Male & 123 & $30.5 \%$ \\
\hline Female & 238 & $69.5 \%$ \\
\hline \multicolumn{3}{|l|}{ Residence } \\
\hline Urban & 342 & $89.6 \%$ \\
\hline Rural & 42 & $10.4 \%$ \\
\hline \multicolumn{3}{|l|}{ Marital status } \\
\hline Unmarried & 56 & 13.9 \\
\hline Married & 151 & 37.5 \\
\hline Divorced & 115 & 28.5 \\
\hline Widowed & 81 & 20.1 \\
\hline \multicolumn{3}{|l|}{ Religion } \\
\hline Orthodox & 377 & 93.5 \\
\hline Muslim & 24 & 6 \\
\hline Others & 2 & 0.5 \\
\hline \multicolumn{3}{|l|}{ Ethnicity } \\
\hline Tigre & 384 & $95.3 \%$ \\
\hline Amhara & 16 & 4 \\
\hline Oromo & 3 & 0.7 \\
\hline \multicolumn{3}{|l|}{ Occupation } \\
\hline Government employee & 60 & 14.9 \\
\hline Private employee & 26 & 6.5 \\
\hline NGO employee & 26 & 6.5 \\
\hline Business man/women & 81 & 20.1 \\
\hline Farmer & 28 & 6.9 \\
\hline Housewife & 67 & 16.6 \\
\hline Daily laborer & 86 & 21.3 \\
\hline Student & 4 & 1 \\
\hline Have no job & 25 & 6.2 \\
\hline \multicolumn{3}{|l|}{ Educational status } \\
\hline Illiterate & 78 & 19.4 \\
\hline Read and write & 42 & 10.4 \\
\hline $1-6$ & 87 & 21.6 \\
\hline $7-8$ & 68 & 16.9 \\
\hline $9-12$ & 83 & 20.6 \\
\hline College and above & 45 & 11.2 \\
\hline
\end{tabular}

\subsection{Clinical Characteristic}

Regarding the treatment ragmen, majority study participants were under AZT-3TC-NVP (37\%) which is followed by TDF-3TC-NVP $(25.8 \%)$. When enrolled for ART more than half of the respondents were stage III of WHO staging and currently about $85 \%$ of the respondents were T1 WHO staging (Table 2).

Table 2. Clinical characteristics of People living with HIV/AIDS in Mekelle hospital, northern Ethiopia

\begin{tabular}{lll}
\hline Variables & Frequency & Percent \\
\hline Regimen of ART & & \\
d4t (30)-3TC-NVP & 54 & 13.4 \\
TDF-3TC-NVP & 104 & 25.8 \\
d4t-3TC-EFP & 7 & 1.7 \\
TDF-3TC-EFV & 49 & 12.2 \\
AZT-3TC-NVP & 149 & 37 \\
AZT-3TC-EFV & 37 & 9.2 \\
2nd line & 3 & 0.7 \\
Initial WHO stage & & \\
Stage I & 22 & 5.5 \\
Stage II & 68 & 16.9 \\
Stage III & 216 & 53.6 \\
Stage IV & 97 & 24.1 \\
Current WHO stage & & \\
Stage I & 7 & 1.7 \\
Stage II & 23 & 5.7 \\
Stage III & 22 & 5.5 \\
Stage IV & 6 & 1.5 \\
T1 & 341 & 84.6 \\
T2 & 4 & 1 \\
\hline
\end{tabular}

\subsection{Drug Adherence}

Drug adherence was assessed by Morisky medication adherence scale which has eight items. Study participants were asked for eight questions which should be answered correctly, the respondents labeled as adherent if they answered eight out of eight; otherwise they were said nonadherent to HAART. Accordingly, about $62 \%$ of individuals were adherent to their AR drug while $37.7 \%$ of them were non-adherent (Table 3).

Table 3. Drug adherence status of PLWHA in Mekelle hospital, Northern Ethiopia, June 2012

\begin{tabular}{lll}
\hline Adherence category & Frequency & Percent \\
\hline Non-adherent & 152 & 37.7 \\
Adherent & 251 & 62.3 \\
Total & 403 & 100.0 \\
\hline
\end{tabular}

\subsection{Factors Associated with Drug Non-Adherence}

Bivariate analysis showed that urban residence were 2.5 more likely to be adherent to their HART than those from rural area. Besides this, patients diagnosed in Mekelle hospital also $1.9(95 \%$ CI: $1.2,2.9)$ time more likely to adhere. In addition, participants whose marital status is being widowed and those who have their own incomes were more likely to adhere to HAART. 
Multiple logistic regression was done to identify the independent predictors by controlling for possible confounding variables. Accordingly, income status (2.1
95\% CI: 1.2, 3.9), residence $(2.3$ 95\% CI: 1.2, 4.5) and diagnosed (1.8 95\% CI: 1.2, 2.9) in Mekelle were independently predicts HAART adherence (Table 4).

Table 4. Bivariate and multiple logistic regression analysis for factors drug adherence among people living with HIV/AIDS in Mekelle Hospital

\begin{tabular}{|c|c|c|c|c|}
\hline \multirow[t]{2}{*}{ Variables } & \multicolumn{2}{|c|}{ Adherent to ART } & \multicolumn{2}{|c|}{ Odds ratio $(95 \% \mathrm{CI})$} \\
\hline & Yes & No & COR & AOR \\
\hline \multicolumn{5}{|l|}{ Age } \\
\hline $20-30$ & $44(10.9 \%)$ & $32(7.9 \%)$ & 1 & \\
\hline $31-40$ & $112(27.8 \%)$ & $76(18.9 \%)$ & $1.1(0.6,1.8)$ & - \\
\hline $41-50$ & $70(17.4 \%)$ & $29(7.2 \%)$ & $1.8(0.9,3.3)$ & - \\
\hline$>50$ & $25(6.2 \%)$ & $15(3.7 \%)$ & $1.2(0.6,2.7)$ & - \\
\hline \multicolumn{5}{|l|}{ Occupation } \\
\hline Employed & $72(17.9 \%)$ & $40(9.9 \%)$ & 1 & \\
\hline Business man/women & $53(13.2 \%)$ & $28(6.9 \%)$ & $1(0.6,1.9)$ & - \\
\hline Farmer & $14(3.5 \%)$ & $14(3.5 \%)$ & $0.6(0.2,1.3)$ & - \\
\hline Housewife & $38(9.4 \%)$ & $29(7.2 \%)$ & $0.7(0.4,1.4)$ & - \\
\hline Daily laborer & $58(14.4 \%)$ & $28(6.9 \%)$ & $1.2(0.6,1)$ & - \\
\hline Have no job & $16(4 \%)$ & $13(3.2 \%)$ & $0.6(0.3,1.6)$ & - \\
\hline \multicolumn{5}{|l|}{ Sex } \\
\hline Male & $75(18.6 \%)$ & $48(11.9 \%)$ & 1 & - \\
\hline Female & $176(43.7 \%)$ & $104(25.8 \%)$ & $1.1(0.7-1.7)$ & - \\
\hline \multicolumn{5}{|l|}{ WHO initial stage } \\
\hline I & $14(3.5 \%)$ & $38(9.4 \%)$ & 1 & \\
\hline II & $8(2 \%)$ & $30(7.4 \%)$ & $0.7(0.3,1.9)$ & - \\
\hline III & $137(34 \%)$ & $79(19.6 \%)$ & $1(0.4,2.5)$ & - \\
\hline IV & $62(15.4 \%)$ & $35(8.7 \%)$ & $1.2(0.3,2.7)$ & - \\
\hline \multicolumn{5}{|c|}{ Diagnosed in Mekelle hospital } \\
\hline Yes & $200(49.6 \%)$ & $103(25.6 \%)$ & $1.9(1.2,2.9)^{*}$ & $1.8(1.2,2.9)^{*}$ \\
\hline No & $51(12.7 \%)$ & $49(12.2 \%)$ & 1 & 1 \\
\hline \multicolumn{5}{|l|}{ Residence } \\
\hline Urban & $233(57.8 \%)$ & $128(31.8 \%)$ & $2.5(1.3,4.6)^{*}$ & $2.3(1.2,4.5)^{*}$ \\
\hline Rural & $18(4.5 \%)$ & $24(6 \%)$ & 1 & 1 \\
\hline \multicolumn{5}{|l|}{ Marital status } \\
\hline Unmarried & $29(7.2 \%)$ & $27(6.7 \%)$ & 1 & 1 \\
\hline Married & $9222.8 \%)$ & $59(14.6 \%)$ & $1.5(0.8,2.7)$ & $1.6(0.9,3)$ \\
\hline Divorced & $42(10.4 \%)$ & $73(18.1 \%)$ & $1.7(0.9,3)$ & $1.7(0.8,3)$ \\
\hline Windowed & $57(14.1 \%$ & $24(6 \%)$ & $2.2(1.1,4.5)^{*}$ & $1.7(0.8,3.1)$ \\
\hline \multicolumn{5}{|l|}{ Own income } \\
\hline Yes & $229(56.8 \%)$ & $124(30.8 \%)$ & $2.4(1.3,4.3)^{*}$ & $2.1(1.2,3.9)^{*}$ \\
\hline No & $22(5.5 \%)$ & $28(6.9 \%)$ & 1 & 1 \\
\hline \multicolumn{5}{|l|}{ Education status } \\
\hline Illiterate & $78(19 \%)$ & $42(10.4)$ & 1 & - \\
\hline Primary & $99(24.6 \%)$ & $56(13.9 \%)$ & $0.9(0.5,1.6)$ & - \\
\hline Secondary and above & $74(18.4 \%)$ & $54(13.4 \%)$ & $0.7(0.44,1.2)$ & - \\
\hline \multicolumn{5}{|l|}{ Living arrangement } \\
\hline Alone & $48(11.9 \%)$ & $33(8.2 \%)$ & $2.7(1.1,6.9)^{*}$ & $2(0.8,5)$ \\
\hline With family & $194(48.1 \%)$ & $102(25.3 \%)$ & $3.6(1.5,8.3)^{*}$ & $3.1(1.3,7)^{*}$ \\
\hline With parents & $9(2.2 \%)$ & $17(4.2 \%)$ & 1 & 1 \\
\hline \multicolumn{5}{|l|}{ Disclosed HIV status } \\
\hline Yes & & & $1.5(0.9,2.5)$ & - \\
\hline No & & & 1 & - \\
\hline
\end{tabular}

*Statistically significant at $95 \%$ confidence interval

\section{Discussion}

This study tried to assess the level of adherence and factors associated with HAART adherence in Mekelle hospital during June 2012. Drug adherence level was assessed by Morisky medication adherence question was used. Based on this, $62 \%$ of individuals were adherent to their ART drugs while $37.7 \%$ of them were non-adherent. This finding is lower than the study done in Jimma hospital, northwest Ethiopia in which $95 \%$ of the participants were adherent (9). The prevalence of adherence is also lower than the study done in northwest Ethiopia which greater than $80 \%$ in Gonder and Felegehiwot hospital (8). This adherence rate also lower than the study done in Yigalem hospital southern Ethiopia (6). But this finding is consistent with study done in Kenya Nairobi (10). The adherence rate is $10 \%$ lower than the pooled report of sub-Saharan Africa (7).

Factors which may associate with adherence were assessed using bivariate and multiple logistic regression analyses. Accordingly income status of the patient, place of 
residence and place of diagnosis were factors associated with drug adherence level of the PLWHA.

We found that income status of the patient increase ART adherence. PLWHAs those have their own income were found to be 2.1 times more likely to adhere. This finding is inconsistence with study done in northwest Ethiopian and Yirgalem hospital, southern Ethiopia $(6,8)$. It is also inconsistent with study done in Nigeria, Kenya and Brazil $(10-12)$. This is may be related with the individuals were giving their attention to their daily basic need living than HAART.

On the other hand, place of residence is another factor related with HAART adherence among PLWHA. Participants from urban residence were more likely to adhere to HAART than those from rural areas. This finding is consistence with study done in Nigeria; living in urban area is related with drug adherence (11). It is also consistence study done in Kwazule Natal, South Africa(13). The explanation behind this may be individuals from urban areas are near to information and place where the service is provided. Also the hospital is found in center of town of Mekelle this may difficult resident to come to collect their drugs easily.

Studies from Northwest Ethiopia, Nigeria, showed that, disclosing HIV status is related with adherence to ART (8, 11). But in this study, HIV disclosing status did not have statistically significant association with adherence to ART.

We identified that places where HIV diagnosis takes placed were significant association with HAART adherence. Patient who diagnosed in Mekelle hospital were more likely to adhere than patients referred from other places after diagnosis for ART services. This may because of the distance from health facility, patient those diagnosed at other health facilities may go far distance to take their ART than those diagnosed in the hospital from which they took their drug. Besides this, patients those took their ART from the place where diagnosed likely to familiar with the facility as a result they may have higher adherence level when compared with those referred from other places.

In this study, we found that educational status, sex of the client and HIV disclosing were not related with the adherence status of the clients. This finding is inconsistence with study done in Nepal in which adherence is related with these factors (14). This finding is consistent with the findings from Yirgalem hospital, northwest Ethiopia and Jimma hospital which were done in Ethiopia; in terms of HIV status disclosure, but inconsistent for other variables $(6,8,9)$.

This study assessed the adherence rate of the PLWHA, but it has certain limitations. Adherence which is assessed by patients' response only may over or under estimate the adherence rate. So the result of this study should be used carefully. Beside this there may desirable bias among patients. Given this limitation our finding is important to identify the problem of non-adherence and to improve the health of PLWHA.

\section{Conclusion}

Adherence level among people living HIV/AIDS low when it compared with the benefit of the HAART. Place of residence, lack of income and place of HIV diagnosis were the independent predictor for drug adherence status. So, action should be taken by professionals and other concerning bodies working on ART services to increase the patients' adherence through awareness creation and designing of income generation methods.

\section{Acknowledgement}

The authors would like to thank Mekelle University for funding this research. Our gratitude goes to supervisors, data collectors, respondents who participated in this study and Tigray regional health bureau and Mekelle Hospital staffs for their contribution in accomplishment of this study.

\section{Competing Interests}

The authors declare that they have no competing interests.

\section{Authors' Contributions}

$\mathrm{KH}^{1}: \mathrm{BE}^{2}: \mathrm{MA}^{1}: \mathrm{GF}^{1}$ : has taken a principal role in the conception of ideas, developing methodologies and writing the article. And they were involved in data collection, analysis, interpretation of the data and preparing in this manuscript. These authors contributed equally to this work and accepted the final manuscript.

\section{References}

[1] UNAIDS. Global report: UNAIDS report on the global AIDS epidemic2012.

[2] Federal Democratic Repulic of Ethiopia. Country Progress Report on HIV/AIDS Response. Addis Ababa 2012.

[3] L. Sherr, F.C. Lampe, C. Clucas, M. Johnson, M. Fisher, H. Leake Date, et al. Self-reported non-adherence to ART and virological outcome in a multiclinic UK study. Care: Psychological and Socio-medical Aspects of AIDS/HIV2010;22(8):939-45.

[4] World health organization. From access to adherence: the challenges of antiretroviral treatment. Anita H, Sheila D, Trudie G, Catherine H, Henry I, Joyce K, et al., editors. Geneva WHO; 2006

[5] Abaasa AM, Todd J, Ekoru K, Kalyango JN, Levin J, Odeke E, et al. Good adherence to HAART and improved survival in a community HIV/AIDS treatment and care programme: the experience of The AIDS Support Organization (TASO), Kampala, Uganda. BMC Health Services Research 2008; 8(241):doi:10.1186/472-6963-8-241.

[6] Markos E, Worku A, Davey G. Adherence to ART in PLWHA at Yirgalem Hospital, South Ethiopia. EthiopJHealth Dev2008;22 (2):174-9. 
[7] Reda AA, Biadgilign S. Determinants of Adherence to Antiretroviral Therapy among HIV-Infected Patients in Africa. AIDS Research and Treatment. [Review ]. 2012;Article ID 574656(doi:10.1155/2012/574656).

[8] Tessema B, Biadglegne F, Mulu A, Getachew A, Emmrich $\mathrm{F}$, Ulrich S. Magnitude and determinants of nonadherence and nonreadiness to highly active antiretroviral therapy among people living with HIV/AIDS in Northwest Ethiopia: a cross - sectional study. AIDS Research and Therapy 2010; $7(2)$.

[9] Tiyou A, Belachew T, Alemseged F, Biadgilign S. Predictors of adherence to antiretroviral therapy among people living with HIV/AIDS in resourcelimited setting of southwest ethiopia. AIDS Research and Therapy 2010; 7(39).

[10] Wakibi S, Ng'ang Z, Mbugua G. Factors associated with non-adherence to highly active antiretroviral therapy in Nairobi, Kenya. AIDS Research and Therapy 2011;8(43):http://www.aidsrestherapy.com/content/8/1/43
[11] Afolabi M, Ijadunola K, Fatusi A, Olasode O. Determinants of adherenceto antiretroviral drugsamong people living withHIV/AIDS in the Ife-Ijesazone of Osun state, Nigeria. Afr J Prm Health Care Fam Med 2009;1(1):Art. \#6, pages. DOI: $10.4102 /$ phcfm.v1i1.6.

[12] Silva Mcf, Ximenes Raa, Miranda Filho Db, Arraes Lwms, Mendes M, Melo Acs, et al. Risk-factors for non-adherence to antiretroviral therapy. Rev Inst Med trop S Paulo 2009;15(3):135-9.

[13] Peltzer K, Friend-du Preez N, Ramlagan S, Anderson J. Antiretroviral treatment adherence among HIV patients in KwaZulu-Natal, South Africa. BMC Public Health 2010; 10(111):http://www.biomedcentral.com/1471-2458/10/111

[14] Wasti S, Simkhada P, Randall J, Freeman J, van Teijlingen E. Factors Influencing Adherence to Antiretroviral Treatment in Nepal: A Mixed-Methods Study. PLoS ONE 2012;7(5):e35547. doi:10.1371/journal.pone.0035547. 